\title{
pharmaceuticals
}

ISSN 1424-8247

www.mdpi.com/journal/pharmaceuticals

Review

\section{Hormesis: Decoding Two Sides of the Same Coin}

\section{Dipita Bhakta-Guha ${ }^{1}$ and Thomas Efferth ${ }^{2, *}$}

1 School of Chemical and Biotechnology, SASTRA University, Thanjavur, Tamil Nadu 613401, India, E-Mail: dipita2001@gmail.com

2 Department of Pharmaceutical Biology, Johannes Gutenberg University, Mainz 55128, Germany

* Author to whom correspondence should be addressed; E-Mail: efferth@uni-mainz.de; Tel.: +49-6131-392-5751; Fax: +49-6131-392-3752.

Academic Editor: Jean Jacques Vanden Eynde

Received: 13 November 2015 / Accepted: 11 December 2015 / Published: 16 December 2015

\begin{abstract}
In the paradigm of drug administration, determining the correct dosage of a therapeutic is often a challenge. Several drugs have been noted to demonstrate contradictory effects per se at high and low doses. This duality in function of a drug at different concentrations is known as hormesis. Therefore, it becomes necessary to study these biphasic functions in order to understand the mechanistic basis of their effects. In this article, we focus on different molecules and pathways associated with diseases that possess a duality in their function and thus prove to be the seat of hormesis. In particular, we have highlighted the pathways and factors involved in the progression of cancer and how the biphasic behavior of the molecules involved can alter the manifestations of cancer. Because of the pragmatic role that it exhibits, the imminent need is to draw attention to the concept of hormesis. Herein, we also discuss different stressors that trigger hormesis and how stress-mediated responses increase the overall adaptive response of an individual to stress stimulus. We talk about common pathways through which cancer progresses (such as nuclear factor erythroid 2-related factor 2-Kelch-like ECH-associated protein 1 (Nrf2-Keap1), sirtuin-forkhead box O (SIRT-FOXO) and others), analyzing how diverse molecules associated with these pathways conform to hormesis.
\end{abstract}

Keywords: hormesis; biphasic; cancer; pathways; stressor; mimetics 


\section{Introduction}

For several decades, it was believed that drug dosage follows a linear pattern, generating enormous ignorance in the knowledge of the responses in the low-dose zone [1]. Nonetheless, in the past few years, several studies have depicted an inverse response to varied drug doses in the same individual, thereby thoroughly discarding the linearity and threshold-response models of dose determination [2,3]. This reaction, known as "biphasic dose response", as revealed by several studies, has shown significance in establishing the modality of a drug [4-7]. This phenomenon determines the optimal dose of a prescribed drug and, thus, very well advocates Philip von Hohenheim's adage "Die Dosis macht das Gift" or "the dose makes the poison" [8].

It is well recorded that mild environmental stress as a result of feeble doses of stressor stimuli often incites adaptive stress response in individuals in order to maintain homeostasis $[9,10]$. It also complies with the fact that while higher doses of an insult can be overtly harmful, small doses of the same can actually promote health, governed by growth and development $[4,11]$. For instance, we all know that oxygen is indispensable for all aerobic life forms. However, it is interesting to note that the same elixir at high concentrations can prove to be toxic, thus establishing that oxygen follows a biphasic dose relationship [12]. Hence, oxygen is considered beneficial at environmental doses and fatal at higher concentrations $[13,14]$. Such a biphasic response brings into light an immensely significant concept called "hormesis", which refers to a phenomenon that is designated by a "low-dose stimulation and high-dose inhibition" [3]. In other words, hormesis is defined as the duality in response by a cell/individual in reply to an impetus (may be endogenous or exogenous) that spurs favorable effects at a low dose and harmful effects at higher measures [15] (Figure 1). Therefore, in contrast to threshold or linear models of dose-response, hormesis is usually represented either by an inverted U- (bell-shaped) or a J-/U-shaped dose-response curve.

Hormesis, in general, might also be elaborated as an adaptive mechanism of a cell or an organism to compensate any imbalance in homeostasis caused by exposure to factors that mediate intermittent mild stresses [10,16,17]. For example, small episodes of mild ischemia referred to as ischemic preconditioning (IPC) have been reported to shield the brain from future severe depletion of blood and, thus, oxygen [10]. In another adaptive biphasic response, mild caloric restriction (CR) in diverse animals was found to be associated with protection against different forms of cancer [18-20]. While extreme dietary (calorie) restriction could manifest into malnutrition, mild restriction, on the contrary, evokes an adaptive response that defends an individual from cancer and other progressive degenerative pathologies, such as neuro-degenerative and geriatric diseases [21]. This also takes us to another subcategory of hormesis, 'mitohormesis', wherein subjecting an individual to sub-lethal volumes of mitochondrial reactive oxygen species (mtROS) increases the lifespan [22,23]. While ROS in general remains one of the fundamental reasons for most of the diseases, exposure to lower volumes tends to reverse its adversity [24]. It is suggested that ROS might induce endoplasmic reticulum (ER) stress, since a functional axis between ER and mitochondrion exists. This also implies that mitohormesis may be in turn associated with ER hormesis (described later) [25,26]. This biphasic character of hormesis thereby emerges prominently as a subject that needs to be well addressed and understood, especially while determining the dosages of any treatment [3]. Furthermore, it becomes mandatory for the determination of the potential effect of a drug in use at its low-dose zone, so as to comprehend its varied behavior (if it exists). Keeping the duality of responses in mind, regulatory bodies, such as the Food and Drug Administration (FDA) and Environmental Protection Agency (EPA) in the USA, have implemented stringent guidelines to take into account the hormetic effects of interventions [27]. 


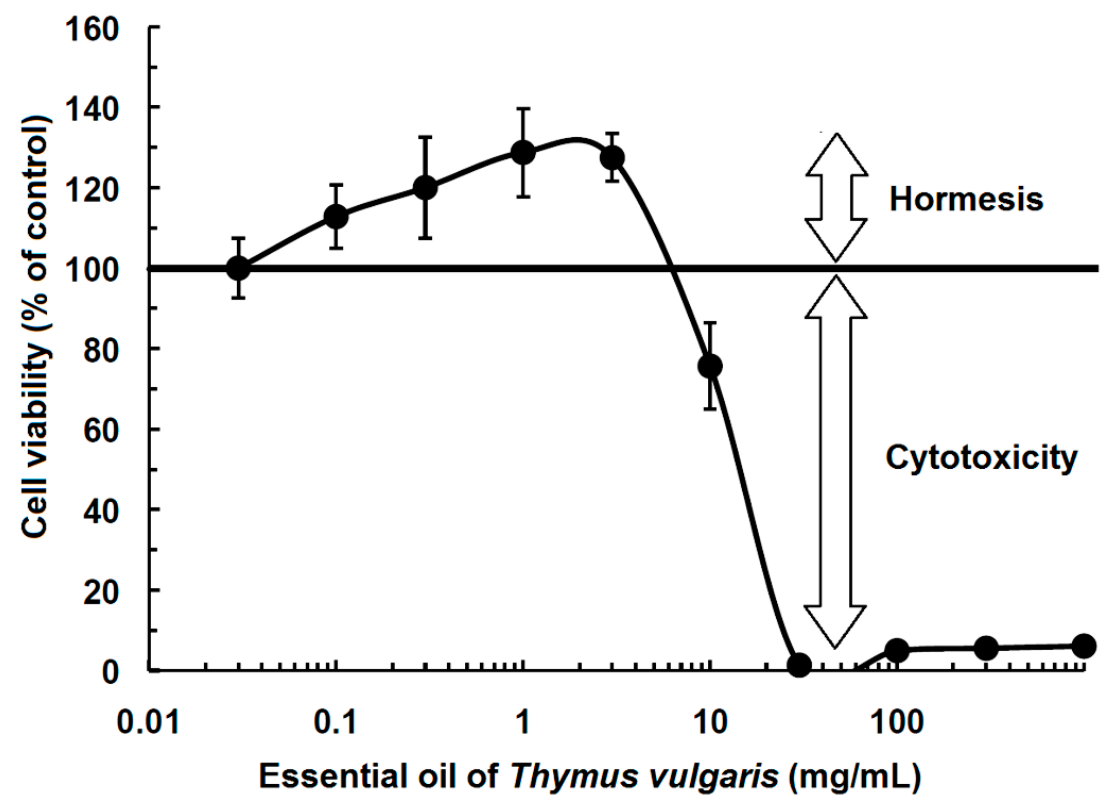

Figure 1. Hormetic effect of essential oil obtained from Thymus vulgaris cell viability (taken and modified with permission of the International Institute of Anticancer Research, Greece). Human UMSCC1 squamous cell carcinoma cells were treated with and without essential oil of Thymus vulgaris and subjected to transcriptome-wide microarray analyses. A total number of 804 genes were differentially regulated in treated cells compared to untreated control cells. These were subjected to ingenuity pathway analysis (IPA) profiling to identify possible pathways. The top three pathways that contribute to the mode of action of the essential oil were: (1) interferon signaling, (2) $\mathrm{N}$-glycan biosynthesis and (3) ERK5 signaling [16].

\section{History}

Mithridates VI, the king of Pontus, since childhood, was suspicious that his mother would poison him to death. In a bid to save himself, he regularly ingested small doses of venom under the supervision of the Shamans of Agari, believing, that this would defend him against all poisons [28]. Since then, the system of administering non-lethal doses of venom in an attempt to avert future poisoning has been termed Mithridatism. Although there is no scientific evidence that substantiates the success of Mithridatism, movies, blogs and a few zoo handlers have continued publicizing the practice. On the scientific arena, however, different responses in the same individual as a consequence of varied dosages of the same drug (not necessarily a poison or toxin), intercepted by time, have often been reported.

The term "hormesis" finds its origin in the Greek word "hormáein" meaning "to set in motion" [10]. In 1854, Rudolf Virchow reported that beating of tracheal epithelial cilia in postmortem mucosa differed under varied sodium and potassium hydroxide concentrations. While at low concentrations, ciliary beatings increased, a dose-dependent decrease in the activity was observed at higher concentrations [29]. Three decades later, Hugo Schulz observed that low dose application of plausible disinfectants actually enhanced metabolism in yeast, which is diametrically opposite to their activity at higher doses [30]. Although initially he discarded the theory believing the result to be an experimental error, repeated studies encouraged him to postulate the Arndt-Schulz law in association with Rudolf 
Arndt. In 1943, Southam and Ehrlich presented the term hormesis for the first time in published literature on their work on the effect of red cider tree extract on fungal proliferation [30]. Despite the prominence revealed in several articles in the subsequent years, focus on hormesis began to get diluted primarily owing to the inability to assess the effect of drugs at their low doses. Most of the 20th century witnessed experiments with the high dose response of drugs and failed to comprehend the significance of clinical manifestations of low-dose drug administration. Furthermore, the overall misguided assumption of hormesis being somehow associated only with homeopathy led to a significant loss of interest in the subject.

Around the 1970s, with the emergence of stringent regulatory measures of drug administration along with improvement in analytical and validation methods, interest in hormesis resurfaced [31]. The assessment of the risk of exposure to carcinogens at very low dose gave impetus to the re-evaluation of the concept in particular [32]. Colossal efforts by Calabrese and others re-established the significance of hormesis and made its estimation a mandatory facet in the precinct of dose determination [7,33-37].

\section{What Triggers Hormesis?}

External effectors (stimuli), such as stressors or aggressors that induce stress at higher concentrations are often called hormetins $[21,38]$. At this juncture, it becomes imperative to establish that the term "stress" in itself can have multiple implications. In the context of this review, we refer to stress as any parameter, extrinsic or intrinsic, that can induce deviation from the normal physiological processes of the body. Exposure to stress often elicits pathways meant to combat the same, which are known as stress-responses [39]. Several of these responses often necessitate stimulation of pro-survival pathways [40]. The hormetins might be of biological, physical or chemical origin $[9,41]$. The generation of the adaptive response to continuous mild exposures to such stressors is an evolutionarily-conserved trait, which in the long run shields an individual against future high concentration-stressor assaults [10]. Although accurate enumeration of components that trigger hormesis might be difficult, hormetins are primarily of the following types:

\subsection{Phytochemicals}

Compounds derived from plants have been a forerunner in the arena of drug discovery owing to the tremendous potential they harbor in terms of combating diverse diseases [42]. Even though several secondary metabolites at higher concentrations are toxic, administering them at regulated lower doses has demonstrated health benefits [43-49]. Many of them, especially the dietary phytochemicals (DPCs), have been reported to be prominent hormetic stressors that affect various molecules and signaling pathways associated with disease progression [49]. DPCs, such as chalcone, resveratrol and piceatannol, have exhibited the potential to kill cancer cells at higher doses and simultaneously confer neuro-protection at a low dose administration [43,45,46]. In addition, curcumin, epigallocatechin gallate, genistein, sulforaphane and others specifically affect the $\mathrm{Nrf} 2$ /antioxidant response element (Nrf2/ARE) pathway $[44,47,48]$.

\subsection{Temperature}

Reaction to heat stress is usually mediated through the heat shock (HS) response pathway, which is an evolutionarily-conserved mechanism [40]. Exposure to heat, in principle, triggers nuclear translocation of HS factors. On binding to DNA, these factors initiate HS gene transcription, thereby 
leading to the translation of HS proteins (HSPs) [50]. Exposing inbred males of Drosophila melanogaster to $37^{\circ} \mathrm{C}$ for $5 \mathrm{~min}$ daily for a stretch of five days/week has been noted to increase their longevity [51]. In addition, pre-exposing human skin fibroblasts to an hour of HS treatment $\left(41-42{ }^{\circ} \mathrm{C}\right)$ could protect the cells from premature senescence and apoptosis [40].

\subsection{Caloric Restriction}

Aging is no longer considered an outcome of long-term accumulation of molecular damage. Recent studies reveal that aging is a consequence of a hyper-activated target of rapamycin (TOR) pathway that initiates the activation of diverse cellular processes contributing to geroconversion in organisms, ranging from yeast to mammal (mTOR in mammals) [52]. In different animal models, such as mice, C. elegans, D. melanogaster, S. cerevisiae, etc., dietary restriction (reduction of nutrients by limiting food and water supply not amounting to malnutrition) or CR (decline in calories without altering amino acids, vitamins and other nutrients) reportedly deactivates the TOR pathway, while subsequently slowing down the process of aging and, thus, extending longevity [53].

\subsection{Exercise}

According to the stress theory [54], response generated on exposure of the body to a chronic stressor can be primarily split into three phases: decreased alarm, increased resistance and exhaustion. While long-duration exercises (18-24 $\mathrm{h}$ continuously) are associated with serious, deleterious exhaustion, a normal exercise regimen actually elicits the adaptive response through controlled moderation of free radicals [55]. Under a normal regimen, each exercise spell is followed by a rest phase, where the body is allowed to cope with the stressor (exercise in this case) and subsequently gets adapted. During regular exercise, ROS-mediated nuclear factor kappa-light chain enhancer of activated B cells $(\mathrm{NF \kappa B})$-dependent upregulation of superoxide dismutase (SOD) and glutathione peroxidase gene expressions defends against antioxidants [56]. In addition, several genes involved with metabolism and mitochondrial biogenesis (peroxisome proliferator-activated receptor- $\gamma /-\delta$ (PPAR- $\gamma /-\delta)$, IL-6 receptor, forkhead box O 1 (FOXO1)) oxidant stress response (interferon regulatory factor 1 (IRF1), metallothioneins) also get upregulated, thereby augmenting the adaptive response of the body [57].

Hence, hormetins eliciting non-severe mild chronic stress develop an adaptive response that effectively aids in preparing the body against plausible future high concentration stressor insults. Regular exposure to weak doses of stressors leads to an increase in the stress response-mediated somatic maintenance function that in the long term renders cells resistant to stress, subsequently slowing down the rate of aging and cellular degeneration asserting their hormetic role [40]. Mechanistically, a special set of protective/pro-survival genes known as "vitagenes" maintain cellular homeostasis under conditions of stress. These genes, which code for HSPs (such as heme oxygenase-1 (HO-1), Hsp32, Hsp70, Hsp72, sirtuin and thioredoxin protein systems), primarily trigger multiple signaling networks that aid in upholding the adaptive response of a system and help in circumventing the possible fatalities of stress-induced anomalies [58]. Out of the many pathways, hormetic behavior of ROS in aging, bone remodeling and progressive degenerative manifestations is governed by vitagenes [59]. 


\section{Hormesis in Stressor-Mediated Pathways}

In order to determine how the beneficial role of hormesis might be extrapolated in mitigating malefic consequences of cellular insults, it becomes pertinent to recognize the different cellular/molecular systems and intervening pathways that ensure a biphasic relationship in generating adaptive responses to a stressor stimulus [30]. Primarily, in the context of the etiology of ailments, such as mitochondria-assisted diseases, aging, neurodegenerative diseases and other associated pathologies, hormesis is found to be an integral part of many of the contributing cell signaling pathways and systems. Since discussing hormesis in all stressor-mediated pathways that promote disease is beyond the scope of a single article, we have chosen only a few representative pathways that are modulated by hormesis and are simultaneously implicated in different diseases, such as cardiovascular diseases, aging, neurodegenerative problems and others.

\subsection{Endoplasmic Reticulum Stress}

Several factors, such as calcium depletion, ROS and mutations in trafficking proteins of the secretory pathway, can generate ER stress. This is characterized by the aggregation of misfolded proteins, which trigger an unfolded protein response (UPR). ER-hormesis was studied for the first time in Drosophila ninaA chaperone mutants where accumulation of misfolded Rhodopsin-1 was observed to induce an adaptive UPR [60]. The latter is a conserved adaptive response that activates three pathways (namely inositol-requiring enzyme 1 (IRE1), protein kinase RNA-like ER kinase (PERK) and activating transcription factor 6 (ATF6)) on sensing disruption to normal ER physiology [61]. IRE1 and ATF6 pathways elicit ER-associated degradation (ERAD) that relocates misfolded proteins from ER to cytoplasm, so that the erroneously-folded proteins can undergo proteasomal degradation [62]. However, PERK phosphorylates elongation factor $2 \alpha$ (EF2 $\alpha$ ) that hinders translation of nascent proteins (Figure 2). Interestingly, cell survival/death is determined by the hormetic role of ER-mediated stress. While a prolonged, strong UPR activation mediates apoptosis by activating DNA damage-inducible transcript 3 (DDIT3), mild stress renders protection in neurodegenerative disease models. Another study in Drosophila and mice models of Parkinson's disease revealed that mild UPR activation could promote autophagy-assisted neuroprotection [63]. From studies involving Drosophila and mice, it is concluded that cellular protection is rendered by the activation of X-box binding protein 1 (XBP1) [61]. In addition, ER hormesis finds special significance as a plausible therapeutic target in cancer intervention. Mutations in G-protein-coupled receptor smoothened (Smo), a member of the hedgehog signaling pathway, is associated with cancer manifestation [61]. This particular protein is clinically relevant since it is closely associated with resistance in chemotherapy. Marada and co-workers have reported that ERAD-specific ubiquitin (Hrd1) could successfully destabilize Smo-mutants through UPR. Interestingly, this destabilization is selectively targeted to mutants without affecting the wild-type D. melanogaster [64]. 


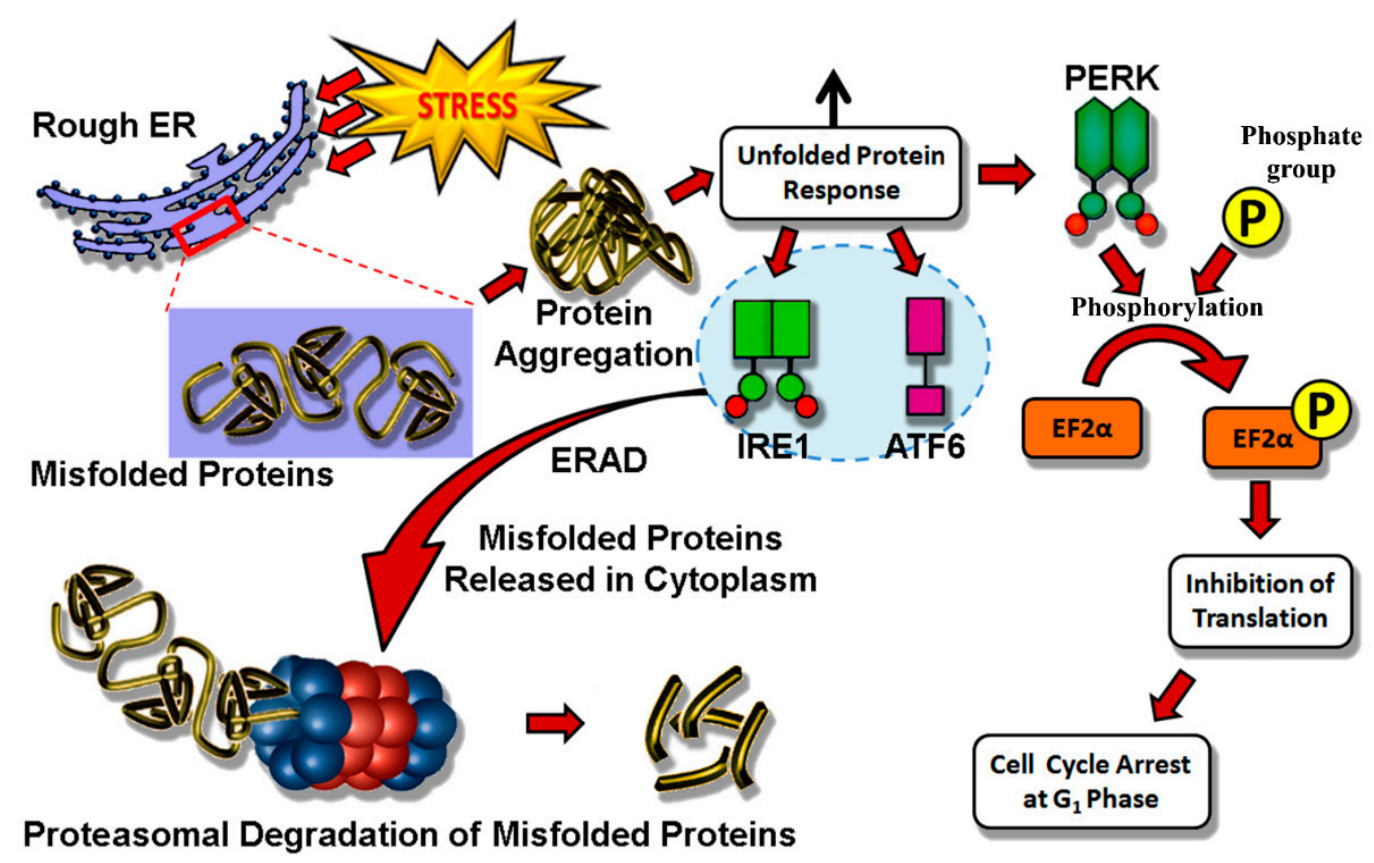

Figure 2. Molecular basis of the endoplasmic reticulum stress mechanism. Accumulation of misfolded proteins leads to upregulation of unfolded protein response (UPR) activating three pathways mediated by IRE1, ATF6 and PERK, respectively. Endoplasmic reticulum-associated degradation (ERAD) pulls out misfolded proteins into the cytoplasm and induces proteasomal degradation.

\subsection{Mitochondria and ROS}

Accumulation of ROS-induced oxidative damage in mtDNA has been earmarked to be a major contributor to aging [65]. Mitochondrial dysfunction is associated with large-scale production of ROS that ultimately promotes cellular degradation [66]. For example, arsenite, a notorious toxin, is known to alter mitochondrial homeostasis (via ROS production and electron transfer chain disruption) [67]. However, administering low doses of arsenite in C. elegans was found to promote longevity [68]. The mechanism behind this biphasic behavior of arsenite was conferred to its ability to activate transcription factors SKN-1 and DAF-16 (orthologs of mammalian Nrf2 and FOXO) [68].

\subsection{Insulin or Insulin-Like Growth Factor 1 Signaling}

Insulin and IGF-1 are produced in pancreas and liver, respectively, and the latter's release is regulated by growth hormone. While impairment of insulin/IGF-1 leads to reduced growth in mice, it simultaneously advocates longevity and protection from neurodegeneration. Similar results were obtained in C. elegans and Drosophila models, as well [69,70]. A large-scale cohort study in humans revealed that polymorphisms in FOXO3A and AKT1 (genes associated with insulin/IGF-1) were markers of increased life span [71].

Thus, hormesis plays a crucial role in the manifestation of a myriad number of diseases. Furthermore, the same biphasic trait enables the onset of beneficial activities in the 'diseased' individual. In the next section, we discuss the role of hormesis in the context of cancer. 


\section{Hormesis and Cancer: A Potential Rescue Path}

Cancer is one of the leading causes of death worldwide, which shows an alarming rate of incidence [72]. It is estimated that by 2030, the number of cancer patients might increase by almost 21 million [73]. While humongous chunks of money are being pushed into the area of cancer research, the complexities of pathways and their cross-talk still obscure any comprehensive mode(s) of cure. Although a number of chemotherapeutic reagents have definitely given a boost in managing the disease, more specific therapeutics are still needed [15]. Moreover, the fact that many research articles have cited the dose-dependent response of the available therapeutics, it becomes all the more pragmatic for regulatory bodies to delve into the possibility of the hormetic effects of the drug [15]. In a recent work carried out by Pearce and co-workers, immune reactants (cancer antibodies) demonstrated alternate stimulatory and inhibitory effects on tumor growth for low and high doses, respectively [74]. Similarly, lithium chloride was also found to be hormetic towards inhibition/induction of apoptosis in breast cancer cells [75]. Herein, we discuss a few critical pathways that play pivotal roles in cancer progression and also act as a seat of hormesis. Since it is impossible to assimilate all pathways that have functional duality associated with them, we categorically look into a few common pathways associated with hormesis.

\subsection{Nrf2-Keap1 Signaling Pathway}

$\mathrm{Nrf} 2$ is a transcription factor that co-ordinates the upregulation of around 200 genes associated with diverse cytoprotective mechanisms [76]. During non-stress conditions, the half-life of Nrf2 remains short, and its levels are regulated by Keap1 (both form a complex together in the cytoplasm) [77]. Additionally, polyubiquitination and proteasomal degradation of $\mathrm{Nrf} 2$ is carried out by the Keap1-Cullin 3/RING-box protein 1 (Rbx1)-E3 ligase complex, ensuring its sequestration in the cytoplasm [78]. However, on events of stress, conformational changes in Keap1 inhibit ubiquitination and subsequent degradation of Nrf2. This allows translocation of the latter into nucleus, where it binds to ARE/EpRE (antioxidant/electrophile response element) eliciting expression of cytoprotective molecules. Interestingly, the duality of Nrf2 lies in the fact that in the case of a carcinogenic stress, Nrf2 mediates the adaptive response through the expression of phase II detoxifying enzymes, rendering protection to cells against carcinogen-mediated genotoxicity [79]. On the contrary, in diverse types of cancer, loss of function of Keap1 was observed to assure prolonged activation of Nrf2, thereby upregulating its downstream genes and subsequently facilitating the growth of neoplastic cells [79-81]. Furthermore, p21 and p62 can bind to Nrf2 and Keap1, respectively, thus blocking Nrf2-Keap1 complex formation and subsequent monitoring of Nrf2 levels by Keap1 [82].

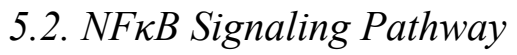

$\mathrm{NF} \kappa \mathrm{B}$ is a transcription factor that forms an inactive cytosolic heterodimer with p65(RelA), RelB and others. This complex stays in association with inhibitors, such as IкB, BCL-3, etc. Stressor (ROS, cytokines, tumor necrosis factor (TNF), Toll-like receptors (TLRs), etc.) mediating the removal of these inhibitors assure activation and subsequent nuclear translocation of NFkB [30]. Usually, inflammatory response is an outcome of $\mathrm{NF \kappa B}$ activation highlighted by the upregulation of $\mathrm{TNF} \alpha$, IL-2/-6, intercellular adhesion molecule 1 (ICAM1), vascular cell adhesion molecule 1 (VCAM1) proteins, cyclooxygenase 2 (COX-2) and inducible nitric oxide synthase (iNOS)-producing enzymes [83]. This is of particular interest, because several proteins upregulated due to NFkB 
activation are actually $\mathrm{NF \kappa B}$ activators. Thus, they initiate an amplified initial response sustaining inflammation, leading to safety against an external/internal stressor. However, the other side of this pathway is the upregulation of certain proteins that inhibit autophagy or apoptosis. Therefore, on the one hand, while NFkB defends cells from stressor by generating inflammation, the same factor is responsible for promoting survival and growth in cancer cells through the induction of the inhibitor of apoptosis proteins (IAPs) and TNFa, respectively [83,84]. This builds up a nexus between inflammation and cancer, with NFkB being the epicenter of hormesis.

\subsection{Sirtuin-FOXO Signaling Pathway}

SIRTs are nicotinamide adenine dinucleotide $\left(\mathrm{NAD}^{+}\right)$-dependent protein deacetylases that cater to a wide range of cellular processes in response to stress [85]. Mammalian sirtuins constitute seven members (SIRT1-7) that vary hugely in terms of their cellular localization and functionality [86]. This family of deacetylases shows a hormetic response to stress, particularly in cancer. Some like SIRT1 confer protection by guarding DNA from stress-mediated damage and oncogene (PML/p53)-induced senescence preventing cancer [87]. SIRT1 has also been observed to promote tumor growth and overall survival and progression of cancer cells [88]. One of the major pathways in cancer progression involves sirtuin and the transcription factor FOXO. FOXO (acts downstream of tumor suppressor phosphatase and tensin homolog (PTEN)) on activation (by SIRT1-mediated deacetylation) translocates into nucleus and upregulates genes associated with DNA repair, cell cycle arrest and apoptosis. However, in prostate cancer cells, deacetylation of FOXO1 by SIRT1 was found to hinder the former's transcriptional and apoptotic activities [89]. This hormetic behavior of tumor promotion/suppression by sirtuins based on the differences in the associated targets and signaling pathways makes them an interesting target in cancer.

\section{Hormetic Compounds in Cancer}

Duality is a trait restricted not only to pathways, but is prevalent among compounds, as well. There are several compounds (natural, as well as synthetic) that, owing to their hormetic property, confer protection to normal cells, as well as are capable of inducing signaling cascades that lead to apoptosis of cancerous cells. In other words, there is a plethora of compounds that inflict different activities in diverse cellular systems owing to the variation in the doses of administration. We take a glance at a few such compounds and their brief modi operandi, particularly under the realms of probable anti-cancer therapeutics (Table 1).

This table is a mere compilation of very few, prominent compounds relevant to cancer therapeutics. As the arena of hormesis is comparatively new (since its re-invention in the 1970s), more impetus needs to be directed towards finding out the biphasic dose response of all drugs to be tested or those that are already commercially available. This information would be a tremendous asset, since the duality in the same compound/pathway can be employed to devise innovative flexible strategies to curb pertinent problems of disease manifestation and progression. 
Table 1. Hormetic compounds with cytotoxic activity towards cancer cells in vitro and in vivo.

\begin{tabular}{|c|c|c|c|c|}
\hline Compound & Low Dose & High Dose & Plausible Mode of Mechanism & Cancer \\
\hline ATN-161 & $\downarrow$ angiogenesis & $\uparrow$ cytotoxic & Integrin inhibitor [90] & Colon \\
\hline Chalcone & non-toxic & cytotoxic & $\begin{array}{l}\text { Nrf2 activation; inhibits NFKB; TRAIL-mediated } \\
\text { hypoxia-induced apoptosis [91] }\end{array}$ & $\begin{array}{l}\text { Ovarian, } \\
\text { hepatic }\end{array}$ \\
\hline Cilengitide & $\uparrow$ angiogenesis & $\downarrow$ angiogenesis & $\begin{array}{l}\text { Inhibits } \alpha v \beta 3 \text { and } \alpha v \beta 5 \text { integrins; endothelial } \\
\text { cell migration [92] }\end{array}$ & $\begin{array}{l}\text { Subcutaneous } \\
\text { tumor graft }\end{array}$ \\
\hline Curcumin & $\begin{array}{l}\uparrow \mathrm{HO}-1, \text { neuro- } \\
\text { protection }\end{array}$ & $\begin{array}{l}\uparrow \text { DNA damage, } \\
\text { apoptosis }\end{array}$ & $\begin{array}{l}\text { Reduces matrix metalloproteinases' expression through } \\
\text { downregulation of NFאB and AP-1 }[93,94]\end{array}$ & Breast \\
\hline Dithiolethione & neuro-protection & cytotoxic & $\begin{array}{l}\text { Increases Nrf2/ARE pathway-mediated transcriptional } \\
\text { activity of phase II enzymes [66] }\end{array}$ & - \\
\hline Endostatin & $\downarrow$ angiogenesis & cytotoxic & Inhibits endothelial cell proliferation, migration [95] & Pancreatic \\
\hline Epigallocatechin & neuro-protection & $\begin{array}{l}\text { pro-oxidant, } \\
\text { 个apoptosis }\end{array}$ & $\begin{array}{l}\text { Phosphorylates Bad at Ser-112,136 through ERK, AKT } \\
\text { pathways; Bcl-2:Bax increases [96] }\end{array}$ & Neuroblastoma \\
\hline Genistein & $\uparrow$ proliferation & $\downarrow$ proliferation & $\begin{array}{l}\text { Increases cleaved PARP expression; inhibits NFKB; } \\
\text { inhibits Akt [97] }\end{array}$ & Prostate \\
\hline Isothiocyanates & $\uparrow$ proliferation & $\downarrow$ proliferation & Alters cell growth and migration pattern [98] & Colon \\
\hline Kaempferol & estrogen agonist & growth inhibitor & $\begin{array}{l}\text { Depletes estrogen-induced malignancy; suppresses } \\
\text { COX-2; induces caspase-3, apoptosis inducing factor } \\
\text { (AIF), MnSOD [99] }\end{array}$ & Breast \\
\hline Metformin & anti-diabetic & anti-cancer & $\begin{array}{l}\text { Suppresses mTOR/S6K1; inhibits tyrosine kinase } \\
\text { receptors HER1/2 [100] }\end{array}$ & $\begin{array}{l}\text { Epidermoid, } \\
\text { breast, prostate }\end{array}$ \\
\hline Quercetin & anti-oxidant & pro-oxidant & $\begin{array}{l}\text { Suppresses NFאB activity, G1 cell cycle arrest, } \uparrow p 21, p 53 \text {; } \\
\text { inhibits ubiquitination [15] }\end{array}$ & $\begin{array}{l}\text { Pancreatic, } \\
\text { colon, hepatic }\end{array}$ \\
\hline Resveratrol & $\begin{array}{l}\uparrow \text { proliferation } \\
\text { cardio protection }\end{array}$ & $\begin{array}{l}\downarrow \text { proliferation } \\
\text { anti-cancer }\end{array}$ & Activates Nrf2; upregulates FOXO $[101,102]$ & endometrial \\
\hline Rosiglitazone & $\downarrow$ angiogenesis & $\uparrow$ cytotoxicity & $\begin{array}{l}\text { Inhibits endothelial proliferation and vascular endothelial } \\
\text { growth factor (VEGF) activation; upregulates matrix } \\
\text { metalloproteinase (MMP) inhibitors [103] }\end{array}$ & $\begin{array}{l}\text { Bladder, breast, } \\
\text { thyroid }\end{array}$ \\
\hline Secoiridoid & $\downarrow$ pro-aging effect & $\uparrow$ cytotoxicity & $\begin{array}{l}\text { Activates ER stress, unfolded protein-mediated response, } \\
\text { SIRT1 and Nrf2 [21] }\end{array}$ & Breast \\
\hline Sulforaphane & $\begin{array}{l}\uparrow \text { proliferation } \\
\text { 个angiogenesis }\end{array}$ & $\begin{array}{l}\downarrow \text { proliferation } \\
\downarrow \text { angiogenesis }\end{array}$ & $\begin{array}{l}\text { Activates Nrf2/ARE pathway; regulates NFкB and AP-1 } \\
\text { to induce apoptosis; activates autophagy [98] }\end{array}$ & Bladder \\
\hline $\begin{array}{l}\text { Thrombo- } \\
\text { spondin-1 }\end{array}$ & $\uparrow$ cell migration & $\downarrow$ cell migration & Inhibits endothelial cell migration. [104] & Oral \\
\hline
\end{tabular}

$\uparrow$ : increase; $\downarrow$ : decrease.

\section{Hormesis Mimetics: A World of Endless Opportunities}

Mimesis (to imitate) in research is a powerful tool, which, if applied judiciously, can work wonders, particularly in understanding disease mechanisms. The compounds/factors that mimic a known factor/pathway/compound are often referred to as mimetics. In the field of hormesis, mimetics are agents that can induce hormetic pathways [35]. Exposure to such agents ensures protective responses, not only to the imminent threat, but may also reverse the functionality errors associated with age/stress/disease to a certain extent [105]. However, it must be remembered that the dose/concentration of the mimetic being administered should itself not be toxic to the body and must be provided in moderate (harmless) quantities. Based on the type of hormetic pathway accessed and 
the factors elicited/inhibited to promote a response, hormesis mimetics can be broadly categorized as follows.

\subsection{Heat Mimetics}

These enhance HSP response to heat stress through the activation of chaperones, leading to lesser aggregation of misfolded proteins. This, in turn, assists in the proteasomal degradation of anomalous proteins subsequently equipping the cell/system for future stresses [35].

\subsection{CR Mimetics}

CR mimetics are molecules that are the biochemical and functional facets of CR. They promote deacetylation of cellular proteins and mediate autophagy. In addition, properties, such as glycolysis inhibition, sirtuin, lipid regulation and insulin-specific gene modulation, enable this group of mimetics to promote longevity, anti-aging and anti-cancer activities [106,107].

\subsection{Radiation Mimetics}

This type of molecule stimulates the resistance pathways of the DNA repair of radiation-induced damage. They also trigger the signaling pathway associated with the gene cascade whose expression ensues longevity and protection from radiation-mediated injuries [108].

\subsection{Hibernation Mimetics}

These cater to a stratagem similar to that of hibernation, which forms a significant policy of evading stress-induced damage. Hibernation is a common phenomenon that is adopted to tackle the problems of hypoxia, hypothermia, intracellular acidosis or muscle wasting. Such agents help in the mitigation of multiple stresses [35].

Apart from the broad categories mentioned above, exercise and immunoregulatory mimetics enhance the overall protective response of an individual exposed to stress. In Table 2, we have enlisted a few mimetics that are common in the field of hormesis and are associated with disease alleviation to a considerable extent.

Table 2. Hibernation mimetics associated with disease alleviation.

\begin{tabular}{|c|c|c|c|}
\hline Compound & Type of Mimetic & Plausible Mode of Mechanism & Disease \\
\hline Carnitine & caloric restriction & $\begin{array}{l}\text { Upregulates HO-1, sirtuin, thioredoxin, } \downarrow \text { pro-oxidant } \\
\text { activity, mediates fatty acid metabolism }[66]\end{array}$ & $\begin{array}{l}\text { Neurodegenerative } \\
\text { damage }\end{array}$ \\
\hline Resveratrol & caloric restriction & $\begin{array}{l}\text { Sirtuin activator, } \downarrow U \mathrm{UV} / \mathrm{H}_{2} \mathrm{O}_{2} \text {-induced apoptosis, } \uparrow \mathrm{SIRT} \\
\text { mediated FOXO activation }[109,110]\end{array}$ & $\begin{array}{l}\text { Longevity, oxidative } \\
\text { damage, toxicity } \\
\text { resistance }\end{array}$ \\
\hline Secoiridoid & caloric restriction & $\begin{array}{l}\uparrow N r f 2 \text {, SIRT1 signaling, mediates ER stress response, } \\
\text { regulates mTOR pathway [21] }\end{array}$ & $\begin{array}{l}\text { Longevity, } \\
\text { age-associated diseases }\end{array}$ \\
\hline $\begin{array}{l}\operatorname{PPAR} \delta \\
\text { agonists }\end{array}$ & caloric restriction & $\downarrow$ Glucose consumption in skeletal muscles [111] & Insulin sensitivity \\
\hline Ethanol & heat & $\begin{array}{l}\uparrow H \text { sp } 70 \text { in brain; } \downarrow \beta \text { amyloid-induced neurotoxicity } \\
\text { and apoptosis [112] }\end{array}$ & Alzheimer's; dementia \\
\hline $\begin{array}{l}\text { Geranyl- } \\
\text { geranylactone } \\
\text { (GGA) }\end{array}$ & heat & $\begin{array}{l}\text { Induces bone osteoblasts, upregulates thioredoxin, } \\
\text { forms apoptosome on binding to Apaf-1, inhibits c-Jun } \\
\text { N-terminal kinase }[113,35]\end{array}$ & $\begin{array}{l}\text { Osteoporosis, increases } \\
\text { immunity, apoptosis in } \\
\text { normal cells }\end{array}$ \\
\hline
\end{tabular}


Table 2. Cont.

\begin{tabular}{|c|c|c|c|}
\hline Compound & $\begin{array}{l}\text { Type of } \\
\text { Mimetic }\end{array}$ & Plausible Mode of Mechanism & Disease \\
\hline $\begin{array}{l}\text { Delta } 2 \text { opioid } \\
\text { receptors } \\
\text { (DADLE) }\end{array}$ & hibernation & $\downarrow$ Neuronal damage. [114] & Neurodegeneration \\
\hline Oltipraz & radiation & $\begin{array}{l}\uparrow N r f 2-A R E \text { binding, } \uparrow \text { transcriptional induction of } \\
\text { carcinogen detoxification gene cascade [115] }\end{array}$ & Oxidative stress, cancer \\
\hline Ferritins & radiation & ARE activation, $\downarrow$ ROS-mediated damage [35] & Oxidative stress \\
\hline $\begin{array}{l}\text { Thiols and } \\
\text { metals }\end{array}$ & radiation & $\begin{array}{l}\uparrow \text { Antioxidant gene expression, } \uparrow \text { glutathione peroxidase } \\
\text { activity }[116,117]\end{array}$ & $\begin{array}{l}\text { Radiation induced } \\
\text { oxidative damage, } \\
\text { cancer }\end{array}$ \\
\hline Oligonucleotides & radiation & $\begin{array}{l}\downarrow \text { Mutagenesis, photo-carcinogenesis, } \uparrow \text { DNA repair, } \\
\text { mitochondria hyperpolarization }[108,118]\end{array}$ & $\begin{array}{l}\text { UV-induced mutation, } \\
\text { cancer }\end{array}$ \\
\hline $\begin{array}{l}\text { Conserved peptide } \\
\text { sequences, } \\
\text { CpG oligo }\end{array}$ & & $\begin{array}{l}\uparrow \mathrm{TH} 2 \text {-mediated inflammation, } \downarrow \text { cytokine dysfunction, } \\
\uparrow \text { adaptive immunity [35] }\end{array}$ & Increases immunity \\
\hline
\end{tabular}

$\uparrow:$ increase; $\downarrow$ : decrease.

\section{Conclusions}

Now that hormesis is gaining prominence in the context of its imperative relevance in the field of biology, it becomes absolutely mandatory to determine the biphasic activities of therapeutics, or pathways, or stressors. It is known from a number of reports that early life epigenetic alterations can impose a long-term effect on genetic and phenotypic expression. Mild stress-mediated hormesis promotes epigenetic adaptations, and the subsequent transcriptional re-organization forms the basis of all hormetic mechanisms [119]. Understanding how hormesis mechanistically governs life processes would unfurl the mystery towards accurately determining the suitable dosages, suitable signaling molecules or maybe suitable agents that can mimic the effect of an otherwise hormetic substance. These would further help in identifying targets and devising effective strategies to ameliorate diseases or their associated complications. After all, complete knowledge about both sides of a coin definitely tells us much more about the coin.

\section{Acknowledgements}

We thank Gunjan Guha, School of Chemical and Biotechnology, SASTRA University, Thanjavur, India, for the preparation of Figure 2.

\section{Conflicts of interest}

The authors declare they have no conflict of interest.

\section{References}

1. Calabrese, E.J.; Baldwin, L.A. The frequency of U-shaped dose responses in the toxicological literature. Toxicol. Sci. Off. J. Soc. Toxicol. 2001, 62, 330-338.

2. Mattson, M.P. Awareness of hormesis will enhance future research in basic and applied neuroscience. Crit. Rev. Toxicol. 2008, 38, 633-639. 
3. Calabrese, V.; Cornelius, C.; Trovato, A.; Cavallaro, M.; Mancuso, C.; Di Rienzo, L.; Condorelli, D.; de Lorenzo, A.; Calabrese, E.J. The hormetic role of dietary antioxidants in free radical-related diseases. Curr. Pharm. Des. 2010, 16, 877-883.

4. Calabrese, E.J. Nitric oxide: biphasic dose responses. Crit. Rev. Toxicol. 2001, 31, 489-501.

5. Huang, S.-S.; Zheng, R.-L. Biphasic regulation of angiogenesis by reactive oxygen species. Pharm. 2006, 61, 223-229.

6. Day, R.M.; Suzuki, Y.J. Cell proliferation, reactive oxygen and cellular glutathione. Dose-Response 2006, 3, 425-442.

7. Calabrese, E.J. Hormesis: From mainstream to therapy. J. Cell Commun. Signal. 2014, 8, 289-291.

8. Gems, D.; Partridge, L. Stress-response hormesis and aging: "that which does not kill us makes us stronger". Cell MeTable 2008, 7, 200-203.

9. Kouda, K.; Iki, M. Beneficial effects of mild stress (hormetic effects): Dietary restriction and health. J. Physiol. Anthropol. 2010, 29, 127-132.

10. Martins, I.; Galluzzi, L.; Kroemer, G. Hormesis, Cell death and aging. Aging 2011, 3, 821-828.

11. Schumacher, B. Transcription-blocking dna damage in aging: a mechanism for hormesis. BioEssays News Rev. Mol. Cell. Dev. Biol. 2009, 31, 1347-1356.

12. Halliwell, B. Reactive species and antioxidants. Redox biology is a fundamental theme of aerobic life. Plant Physiol. 2006, 141, 312-322.

13. Freiberger, J.; Coulombe, K.; Suliman, H.; Carraway, M.; Piantadosi, C. Superoxide dismutase responds to hyperoxia in rat hippocampus. J. Undersea Hyperb. Med. Soc. Inc. 2004, 31, 227-232.

14. Mach, W.J.; Thimmesch, A.R.; Pierce, J.T.; Pierce, J.D. Consequences of hyperoxia and the toxicity of oxygen in the lung. Nurs. Res. Pract. 2011, 2011, 260482, doi:10.1155/2011/260482.

15. Speciale, A.; Chirafisi, J.; Saija, A.; Cimino, F. Nutritional antioxidants and adaptive cell responses: an update. Curr. Mol. Med. 2011, 11, 770-789.

16. Sertel, S.; Eichhorn, T.; Plinkert, P.K.; Efferth, T. Cytotoxicity of Thymus vulgaris essential oil towards human oral cavity squamous cell carcinoma. Anticancer Res. 2011, 31, 81-87.

17. Mattson, M.P.; Cheng, A. Neurohormetic phytochemicals: low-dose toxins that induce adaptive neuronal stress responses. Trends Neurosci. 2006, 29, 632-639.

18. Hursting, S.D.; Smith, S.M.; Lashinger, L.M.; Harvey, A.E.; Perkins, S.N. Calories and carcinogenesis: lessons learned from 30 years of calorie restriction research. Carcinogenesis 2010, 31, 83-89.

19. Longo, V.D.; Fontana, L. Calorie restriction and cancer prevention: metabolic and molecular mechanisms. Trends Pharmacol. Sci. 2010, 31, 89-98.

20. Yamaza, H.; Komatsu, T.; Wakita, S.; Kijogi, C.; Park, S.; Hayashi, H.; Chiba, T.; Mori, R.; Furuyama, T.; Mori, N.; et al. FoxO1 is involved in the antineoplastic effect of calorie restriction. Aging Cell 2010, 9, 372-382.

21. Menendez, J.A.; Joven, J.; Aragonès, G.; Barrajón-Catalán, E.; Beltrán-Debón, R.; Borrás-Linares, I.; Camps, J.; Corominas-Faja, B.; Cufí, S.; Fernández-Arroyo, S.; et al. Xenohormetic and anti-aging activity of secoiridoid polyphenols present in extra virgin olive oil: A new family of gerosuppressant agents. Cell Cycle Georget. Tex. 2013, 12, 555-578. 
22. Schulz, T.J.; Zarse, K.; Voigt, A.; Urban, N.; Birringer, M.; Ristow, M. Glucose restriction extends caenorhabditis elegans life span by inducing mitochondrial respiration and increasing oxidative stress. Cell MeTable 2007, 6, 280-293.

23. Sohal, R.S.; Orr, W.C. The redox stress hypothesis of aging. Free Radic. Biol. Med. 2012, 52, 539-555.

24. Ristow, M.; Schmeisser, K. Mitohormesis: Promoting health and lifespan by increased levels of reactive oxygen species (ROS). Dose-Response Publ. Int. Hormesis Soc. 2014, 12, 288-341.

25. Hetz, C.; Mollereau, B. Disturbance of endoplasmic reticulum proteostasis in neurodegenerative diseases. Nat. Rev. Neurosci. 2014, 15, 233-249.

26. Mollereau, B.; Manié, S.; Napoletano, F. Getting the better of ER stress. J. Cell Commun. Signal. 2014, 8, 311-321.

27. Maynard, K.I. Hormesis pervasiveness and its potential implications for pharmaceutical research and development. Dose-Response Publ. Int. Hormesis Soc. 2011, 9, 377-386.

28. Mayor, A. The Poison King: The Life and Legend of Mithradates, Rome's Deadliest Enemy; Princeton University Press: Princeton, NJ, USA, 2010; p. 242.

29. Henschler, D. The origin of hormesis: Historical background and driving forces. Hum. Exp. Toxicol. 2006, 25, 347-351.

30. Calabrese, V.; Cornelius, C.; Dinkova-Kostova, A.T.; Calabrese, E.J.; Mattson, M.P. Cellular stress responses, the hormesis paradigm, and vitagenes: Novel targets for therapeutic intervention in neurodegenerative disorders. Antioxid. Redox Signal. 2010, 13, 1763-1811.

31. Costantini, D. Oxidative Stress and Hormesis in Evolutionary Ecology and Physiology: A Marriage Between Mechanistic and Evolutionary Approaches, 1st ed.; Springer Science \& Business Media: Berlin, Germany, 2014.

32. Luch, A. Molecular toxicology. In Molecular, Clinical and Environmental Toxicology; Springer Science \& Business Media: Berlin, Germany, 2012; Volume 1.

33. Laughlin, R.B.; Ng, J.; Guard, H.E. Hormesis: A response to low environmental concentrations of petroleum hydrocarbons. Science 1981, 211, 705-707.

34. Stebbing, A.R. Hormesis - the stimulation of growth by low levels of inhibitors. Sci. Total Environ. 1982, 22, 213-234.

35. Sonneborn, J.S. Mimetics of hormetic agents: Stress-resistance triggers. Dose-Response Publ. Int. Hormesis Soc. 2010, 8, 97-121.

36. Calabrese, E.J. Hormetic mechanisms. Crit. Rev. Toxicol. 2013, 43, 580-606.

37. Calabrese, E.J.; Dhawan, G.; Kapoor, R.; Iavicoli, I.; Calabrese, V. Hormesis: A fundamental concept with widespread biological and biomedical applications. Gerontology 2015, doi:10.1159/000441520.

38. Mattson, M.P. Hormesis defined. Ageing Res. Rev. 2008, 7, 1-7.

39. Dattilo, S.; Mancuso, C.; Koverech, G.; Di Mauro, P.; Ontario, M.L.; Petralia, C.C.; Petralia, A.; Maiolino, L.; Serra, A.; Calabrese, E.J.; et al. Heat shock proteins and hormesis in the diagnosis and treatment of neurodegenerative diseases. Immun. Ageing A 2015, 12, 20 , doi:10.1186/s12979-015-0046-8.

40. Rattan, S.I.S. Hormetic modulation of aging and longevity by mild heat stress. Dose-Response 2006, 3, 533-546. 
41. Richardson, R.B. Ionizing radiation and aging: rejuvenating an old idea. Aging 2009, 1, 887-902.

42. Heber, D. Vegetables, fruits and phytoestrogens in the prevention of diseases. J. Postgrad. Med. 2004, 50, 145-149.

43. Parker, J.A.; Arango, M.; Abderrahmane, S.; Lambert, E.; Tourette, C.; Catoire, H.; Néri, C. Resveratrol rescues mutant polyglutamine cytotoxicity in nematode and mammalian neurons. Nat. Genet. 2005, 37, 349-350.

44. Hu, R.; Xu, C.; Shen, G.; Jain, M.R.; Khor, T.O.; Gopalkrishnan, A.; Lin, W.; Reddy, B.; Chan, J.Y.; Kong, A.-N.T. Gene expression profiles induced by cancer chemopreventive isothiocyanate sulforaphane in the liver of $\mathrm{C} 57 \mathrm{BL} / 6 \mathrm{~J}$ mice and $\mathrm{C} 57 \mathrm{BL} / 6 \mathrm{~J} / \mathrm{Nrf2}(-/-)$ mice. Cancer Lett. 2006, 243, 170-192.

45. Kim, H.J.; Lee, K.W.; Lee, H.J. Protective effects of piceatannol against beta-amyloid-induced neuronal cell death. Ann. N. Y. Acad. Sci. 2007, 1095, 473-482.

46. Wang, C.; Zhang, D.; Li, G.; Liu, J.; Tian, J.; Fu, F.; Liu, K. Neuroprotective effects of safflor yellow b on brain ischemic injury. Exp. Brain Res. 2007, 177, 533-539.

47. Nair, S.; Li, W.; Kong, A.-N.T. Natural dietary anti-cancer chemopreventive compounds: Redox-mediated differential signaling mechanisms in cytoprotection of normal cells versus cytotoxicity in tumor cells. Acta Pharmacol. Sin. 2007, 28, 459-472.

48. Juge, N.; Mithen, R.F.; Traka, M. Molecular basis for chemoprevention by sulforaphane: a comprehensive review. Cell. Mol. Life Sci. CMLS 2007, 64, 1105-1127.

49. Son, T.G.; Camandola, S.; Mattson, M.P. Hormetic dietary phytochemicals. Neuromolecular Med. 2008, 10, 236-246.

50. Park, H.G.; Han, S.I.; Oh, S.Y.; Kang, H.S. Cellular responses to mild heat stress. Cell. Mol. Life Sci. CMLS 2005, 62, 10-23.

51. Le Bourg, E.; Valenti, P.; Lucchetta, P.; Payre, F. Effects of mild heat shocks at young age on aging and longevity in Drosophila melanogaster. Biogerontology 2001, 2, 155-164.

52. Blagosklonny, M.V. Hormesis does not make sense except in the light of tor-driven aging. Aging 2011, 3, 1051-1062.

53. Moskalev, A.A.; Shaposhnikov, M.V. Pharmacological inhibition of phosphoinositide 3 and tor kinases improves survival of Drosophila melanogaster. Rejuvenation Res. 2010, 13, 246-247.

54. Selye, H. The Stress of Life. Hans Selye, M.D. New York, McGraw-Hill Book Company, Inc. 1956. \$5.95. J. Bone Jt. Surg. 1957, 39, 479-479.

55. Radak, Z.; Chung, H.Y.; Koltai, E.; Taylor, A.W.; Goto, S. Exercise, oxidative stress and hormesis. Ageing Res. Rev. 2008, 7, 34-42.

56. Gomez-Cabrera, M.-C.; Martínez, A.; Santangelo, G.; Pallardó, F.V.; Sastre, J.; Viña, J. Oxidative stress in marathon runners: interest of antioxidant supplementation. Br. J. Nutr. 2006, 96, S31-S33.

57. Mahoney, D.J.; Parise, G.; Melov, S.; Safdar, A.; Tarnopolsky, M.A. Analysis of global mrna expression in human skeletal muscle during recovery from endurance exercise. FASEB J. Off. Publ. Fed. Am. Soc. Exp. Biol. 2005, 19, 1498-1500.

58. Mancuso, C.; Pani, G.; Calabrese, V. Bilirubin: an endogenous scavenger of nitric oxide and reactive nitrogen species. Redox Rep. Commun. Free Radic. Res. 2006, 11, 207-213. 
59. Cornelius, C.; Koverech, G.; Crupi, R.; di Paola, R.; Koverech, A.; Lodato, F.; Scuto, M.; Salinaro, A.T.; Cuzzocrea, S.; Calabrese, E.J.; et al. Osteoporosis and alzheimer pathology: Role of cellular stress response and hormetic redox signaling in aging and bone remodeling. Front. Pharmacol. 2014, 5, 120, doi:10.3389/fphar.2014.00120.

60. Mendes, C.S.; Levet, C.; Chatelain, G.; Dourlen, P.; Fouillet, A.; Dichtel-Danjoy, M.-L.; Gambis, A.; Ryoo, H.D.; Steller, H.; Mollereau, B. ER stress protects from retinal degeneration. EMBO J. 2009, 28, 1296-1307.

61. Mollereau, B. Establishing links between endoplasmic reticulum-mediated hormesis and cancer. Mol. Cell. Biol. 2013, 33, 2372-2374.

62. Walter, P.; Ron, D. The unfolded protein response: From stress pathway to homeostatic regulation. Science 2011, 334, 1081-1086.

63. Fouillet, A.; Levet, C.; Virgone, A.; Robin, M.; Dourlen, P.; Rieusset, J.; Belaidi, E.; Ovize, M.; Touret, M.; Nataf, S.; et al. ER stress inhibits neuronal death by promoting autophagy. Autophagy 2012, 8, 915-926.

64. Marada, S.; Stewart, D.P.; Bodeen, W.J.; Han, Y.-G.; Ogden, S.K. The unfolded protein response selectively targets active smoothened mutants. Mol. Cell. Biol. 2013, 33, 2375-2387.

65. Harman, D. Aging: A theory based on free radical and radiation chemistry. J. Gerontol. 1956, 11, 298-300.

66. Cornelius, C.; Perrotta, R.; Graziano, A.; Calabrese, E.J.; Calabrese, V. Stress responses, vitagenes and hormesis as critical determinants in aging and longevity: mitochondria as a "chi". Immun. Ageing 2013, 10, 15, doi:10.1186/1742-4933-10-15.

67. Hosseini, M.-J.; Shaki, F.; Ghazi-Khansari, M.; Pourahmad, J. Toxicity of arsenic (iii) on isolated liver mitochondria: a new mechanistic approach. Iran. J. Pharm. Res. IJPR 2013, 12, 121-138.

68. Schmeisser, S.; Schmeisser, K.; Weimer, S.; Groth, M.; Priebe, S.; Fazius, E.; Kuhlow, D.; Pick, D.; Einax, J.W.; Guthke, R.; et al. Mitochondrial hormesis links low-dose arsenite exposure to lifespan extension. Aging Cell 2013, 12, 508-517.

69. Kenyon, C.; Chang, J.; Gensch, E.; Rudner, A.; Tabtiang, R.A. C. elegans mutant that lives twice as long as wild type. Nature 1993, 366, 461-464.

70. Tatar, M.; Kopelman, A.; Epstein, D.; Tu, M.P.; Yin, C.M.; Garofalo, R.S. A mutant drosophila insulin receptor homolog that extends life-span and impairs neuroendocrine function. Science 2001, 292, 107-110.

71. Pawlikowska, L.; Hu, D.; Huntsman, S.; Sung, A.; Chu, C.; Chen, J.; Joyner, A.H.; Schork, N.J.; Hsueh, W.-C.; Reiner, A.P.; et al. Association of common genetic variation in the insulin/IGF1 signaling pathway with human longevity. Aging Cell 2009, 8, 460-472.

72. Bhakta-Guha, D.; Saeed, M.E. M.; Greten, H.J.; Efferth, T. Dis-organizing centrosomal clusters: Specific cancer therapy for a generic spread? Curr. Med. Chem. 2015, 22, 685-694.

73. Bray, F.; Jemal, A.; Grey, N.; Ferlay, J.; Forman, D. Global cancer transitions according to the human development index (2008-2030): A population-based study. Lancet Oncol. 2012, 13, 790-801. 
74. Pearce, O.M. T.; Läubli, H.; Verhagen, A.; Secrest, P.; Zhang, J.; Varki, N.M.; Crocker, P.R.; Bui, J.D.; Varki, A. Inverse hormesis of cancer growth mediated by narrow ranges of tumor-directed antibodies. Proc. Natl. Acad. Sci. USA 2014, 111, 5998-6003.

75. Suganthi, M.; Sangeetha, G.; Gayathri, G.; Ravi Sankar, B. Biphasic dose-dependent effect of lithium chloride on survival of human hormone-dependent breast cancer cells (MCF-7). Biol. Trace Elem. Res. 2012, 150, 477-486.

76. Hine, C.M.; Mitchell, J.R. NRF2 and the phase II response in acute stress resistance induced by dietary restriction. J. Clin. Exp. Pathol. 2012, S4, 7329, doi:10.4172/2161-0681.S4-004.

77. Lewis, K.N.; Mele, J.; Hayes, J.D.; Buffenstein, R. Nrf2, a guardian of healthspan and gatekeeper of species longevity. Integr. Comp. Biol. 2010, 50, 829-843.

78. Tong, K.I.; Kobayashi, A.; Katsuoka, F.; Yamamoto, M. Two-site substrate recognition model for the keap1-nrf2 system: A hinge and latch mechanism. Biol. Chem. 2006, 387, 1311-1320.

79. Lau, A.; Villeneuve, N.F.; Sun, Z.; Wong, P.K.; Zhang, D.D. Dual roles of Nrf2 in cancer. Pharmacol. Res. Off. J. Ital. Pharmacol. Soc. 2008, 58, 262-270.

80. Wang, X.-J.; Sun, Z.; Villeneuve, N.F.; Zhang, S.; Zhao, F.; Li, Y.; Chen, W.; Yi, X.; Zheng, W.; Wondrak, G.T.; et al. Nrf2 enhances resistance of cancer cells to chemotherapeutic drugs, the dark side of Nrf2. Carcinogenesis 2008, 29, 1235-1243.

81. Pi, J.; Diwan, B.A.; Sun, Y.; Liu, J.; Qu, W.; He, Y.; Styblo, M.; Waalkes, M.P. Arsenic-induced malignant transformation of human keratinocytes: involvement of nrf2. Free Radic. Biol. Med. 2008, 45, 651-658.

82. Kansanen, E.; Kuosmanen, S.M.; Leinonen, H.; Levonen, A.-L. The Keap1-Nrf2 pathway: Mechanisms of activation and dysregulation in cancer. Redox Biol. 2013, 1, 45-49.

83. Brigelius-Flohé, R.; Flohé, L. Basic principles and emerging concepts in the redox control of transcription factors. Antioxid. Redox Signal. 2011, 15, 2335-2381.

84. Nakano, H.; Nakajima, A.; Sakon-Komazawa, S.; Piao, J.-H.; Xue, X.; Okumura, K. Reactive oxygen species mediate crosstalk between NF-kappaB and JNK. Cell Death Differ. 2006, 13, 730-737.

85. Oellerich, M.F.; Potente, M. FOXOs and sirtuins in vascular growth, maintenance, and aging. Circ. Res. 2012, 110, 1238-1251.

86. Bosch-Presegué, L.; Vaquero, A. The dual role of sirtuins in cancer. Genes Cancer 2011, 2, 648-662.

87. Langley, E.; Pearson, M.; Faretta, M.; Bauer, U.-M.; Frye, R.A.; Minucci, S.; Pelicci, P.G.; Kouzarides, T. Human SIR2 deacetylates p53 and antagonizes PML/p53-induced cellular senescence. EMBO J. 2002, 21, 2383-2396.

88. Lin, Z.; Fang, D. The roles of SIRT1 in cancer. Genes Cancer 2013, 4, 97-104.

89. Yang, Y.; Hou, H.; Haller, E.M.; Nicosia, S.V.; Bai, W. Suppression of FOXO1 activity by FHL2 through SIRT1-mediated deacetylation. EMBO J. 2005, 24, 1021-1032.

90. Doñate, F.; Parry, G.C.; Shaked, Y.; Hensley, H.; Guan, X.; Beck, I.; Tel-Tsur, Z.; Plunkett, M.L.; Manuia, M.; Shaw, D.E.; et al. Pharmacology of the novel antiangiogenic peptide ATN-161 (Ac-PHSCN-NH2): Observation of a U-shaped dose-response curve in several preclinical models of angiogenesis and tumor growth. Clin. Cancer Res. 2008, 14, 2137-2144. 
91. Prabhakar, V.; Balasubramanian, R.; Sathe, P.; Murali Krishna, C.; Juvekar, A. In vitro anticancer activity of monosubstituted chalcone derivatives. Int. J. Tumor Ther. 2014, 3, 1-9.

92. Reynolds, A.R.; Hart, I.R.; Watson, A.R.; Welti, J.C.; Silva, R.G.; Robinson, S.D.; da Violante, G.; Gourlaouen, M.; Salih, M.; Jones, M.C.; et al. Stimulation of tumor growth and angiogenesis by low concentrations of RGD-mimetic integrin inhibitors. Nat. Med. 2009, 15, 392-400.

93. Bachmeier, B.; Nerlich, A.G.; Iancu, C.M.; Cilli, M.; Schleicher, E.; Vené, R.; Dell'Eva, R.; Jochum, M.; Albini, A.; Pfeffer, U. The chemopreventive polyphenol curcumin prevents hematogenous breast cancer metastases in immunodeficient mice. Cell. Physiol. Biochem. Int. J. Exp. Cell. Physiol. Biochem. Pharmacol. 2007, 19, 137-152.

94. Bayet-Robert, M.; Morvan, D. Metabolomics reveals metabolic targets and biphasic responses in breast cancer cells treated by curcumin alone and in association with docetaxel. PLoS ONE 2013, 8, e57971.

95. Celik, I.; Sürücü, O.; Dietz, C.; Heymach, J.V.; Force, J.; Höschele, I.; Becker, C.M.; Folkman, J.; Kisker, O. Therapeutic efficacy of endostatin exhibits a biphasic dose-response curve. Cancer Res. 2005, 65, 11044-11050.

96. Weinreb, O.; Amit, T.; Mandel, S.; Youdim, M.B.H. Neuroprotective molecular mechanisms of (-)-epigallocatechin-3-gallate: a reflective outcome of its antioxidant, iron chelating and neuritogenic properties. Genes Nutr. 2009, 4, 283-296.

97. El Touny, L.H.; Banerjee, P.P. Identification of a biphasic role for genistein in the regulation of prostate cancer growth and metastasis. Cancer Res. 2009, 69, 3695-3703.

98. Bao, Y.; Wang, W.; Zhou, Z.; Sun, C. Benefits and risks of the hormetic effects of dietary isothiocyanates on cancer prevention. PLoS ONE 2014, 9, e114764.

99. Oh, S.M.; Kim, Y.P.; Chung, K.H. Biphasic effects of kaempferol on the estrogenicity in human breast cancer cells. Arch. Pharm. Res. 2006, 29, 354-362.

100. Martin-Castillo, B.; Vazquez-Martin, A.; Oliveras-Ferraros, C.; Menendez, J.A. Metformin and cancer: doses, mechanisms and the dandelion and hormetic phenomena. Cell Cycle Georget. Tex. 2010, 9, 1057-1064.

101. Calabrese, E.J.; Mattson, M.P.; Calabrese, V. Resveratrol commonly displays hormesis: Occurrence and biomedical significance. Hum. Exp. Toxicol. 2010, 29, 980-1015.

102. Mukherjee, S.; Dudley, J.I.; Das, D.K. Dose-dependency of resveratrol in providing health benefits. Dose-Response 2010, 8, 478-500.

103. Panigrahy, D.; Singer, S.; Shen, L.Q.; Butterfield, C.E.; Freedman, D.A.; Chen, E.J.; Moses, M.A.; Kilroy, S.; Duensing, S.; Fletcher, C.; et al. PPAR $\gamma$ ligands inhibit primary tumor growth and metastasis by inhibiting angiogenesis. J. Clin. Invest. 2002, 110, 923-932.

104. Motegi, K.; Harada, K.; Ohe, G.; Jones, S.J.; Ellis, I.R.; Crouch, D.H.; Schor, S.L.; Schor, A.M. Differential involvement of tgf-betal in mediating the motogenic effects of tsp-1 on endothelial cells, fibroblasts and oral tumour cells. Exp. Cell Res. 2008, 314, 2323-2333.

105. Mattson, M.P.; Calabrese, E.J. Hormesis: A Revolution in Biology, Toxicology and Medicine, 1st ed.; Springer Science \& Business Media: Berlin, Germany, 2009.

106. Ingram, D.K.; Zhu, M.; Mamczarz, J.; Zou, S.; Lane, M.A.; Roth, G.S.; deCabo, R. Calorie restriction mimetics: An emerging research field. Aging Cell 2006, 5, 97-108. 
107. Testa, G.; Biasi, F.; Poli, G.; Chiarpotto, E. Calorie restriction and dietary restriction mimetics: A strategy for improving healthy aging and longevity. Curr. Pharm. Des. 2014, 20, 2950-2977.

108. Goukassian, D.A.; Helms, E.; van Steeg, H.; van Oostrom, C.; Bhawan, J.; Gilchrest, B.A. topical DNA oligonucleotide therapy reduces UV-induced mutations and photocarcinogenesis in hairless mice. Proc. Natl. Acad. Sci. USA 2004, 101, 3933-3938.

109. Van der Horst, A.; Tertoolen, L.G. J.; de Vries-Smits, L.M. M.; Frye, R.A.; Medema, R.H.; Burgering, B.M. T. FOXO4 is acetylated upon peroxide stress and deacetylated by the longevity protein hSir2(SIRT1). J. Biol. Chem. 2004, 279, 28873-28879.

110. Guarente, L.; Picard, F. Calorie restriction - the SIR2 connection. Cell 2005, 120, 473-482.

111. Brunmair, B.; Staniek, K.; Dörig, J.; Szöcs, Z.; Stadlbauer, K.; Marian, V.; Gras, F.; Anderwald, C.; Nohl, H.; Waldhäusl, W.; et al. Activation of PPAR- $\delta$ in isolated rat skeletal muscle switches fuel preference from glucose to fatty acids. Diabetologia 2006, 49, 2713-2722.

112. Belmadani, A.; Kumar, S.; Schipma, M.; Collins, M.A.; Neafsey, E.J. Inhibition of amyloid- $\beta$-induced neurotoxicity and apoptosis by moderate ethanol preconditioning. Neuroreport 2004, 15, 2093-2096.

113. Wang, X.; Wu, J.; Shidoji, Y.; Muto, Y.; Ohishi, N.; Yagi, K.; Ikegami, S.; Shinki, T.; Udagawa, N.; Suda, T.; et al. Effects of geranylgeranoic acid in bone: induction of osteoblast differentiation and inhibition of osteoclast formation. J. Bone Miner. Res. Off. J. Am. Soc. Bone Miner. Res. 2002, 17, 91-100.

114. Borlongan, C.V.; Wang, Y.; Su, T.-P. Delta opioid peptide (D-Ala 2, D-Leu 5) Enkephalin: Linking hibernation and neuroprotection. Front. Biosci. J. Virtual Libr. 2004, 9, 3392-3398.

115. Kwak, M.K.; Egner, P.A.; Dolan, P.M.; Ramos-Gomez, M.; Groopman, J.D.; Itoh, K.; Yamamoto, M.; Kensler, T.W. Role of phase 2 enzyme induction in chemoprotection by dithiolethiones. Mutat. Res. 2001, 480-481, 305-315.

116. Hamilton, K.L. Antioxidants and cardioprotection. Med. Sci. Sports Exerc. 2007, 39, 1544-1553.

117. Tiwari, P.; Kumar, A.; Balakrishnan, S.; Kushwaha, H.S.; Mishra, K.P. Radiation-induced micronucleus formation and dna damage in human lymphocytes and their prevention by antioxidant thiols. Mutat. Res. 2009, 676, 62-68.

118. Aoki, H.; Iwado, E.; Eller, M.S.; Kondo, Y.; Fujiwara, K.; Li, G.-Z.; Hess, K.R.; Siwak, D.R.; Sawaya, R.; Mills, G.B.; et al. Telomere 3' overhang-specific DNA oligonucleotides induce autophagy in malignant glioma cells. FASEB J. Off. Publ. Fed. Am. Soc. Exp. Biol. 2007, 21, 2918-2930.

119. Vaiserman, A.M. Hormesis, adaptive epigenetic reorganization, and implications for human health and longevity. Dose-Response 2010, 8, 16-21.

(C) 2015 by the authors; licensee MDPI, Basel, Switzerland. This article is an open access article distributed under the terms and conditions of the Creative Commons Attribution license (http://creativecommons.org/licenses/by/4.0/). 